ISSN: 2578-0263

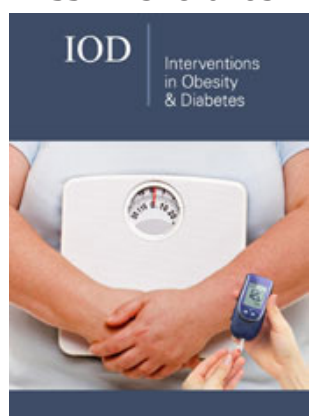

*Corresponding author: Khalid S Aljabri, Department of Endocrinology, King Fahad Armed Forces Hospital, Jeddah, Saudi Arabia

Submission: 制 February 26, 2019

Published: 漹April 2, 2019

Volume 2 - Issue 5

How to cite this article: Khalid $S$ A, Samia A B, Bandari K A, Turki A A. The Association between Subclinical Hypothyroidism and Components of Metabolic Syndrome. 2(5). IOD. 000546. 2019.

DOI: 10.31031/IOD.2019.02.000546

Copyright@ Khalid S Aljabri, This article is distributed under the terms of the Creative Commons Attribution 4.0 International License, which permits unrestricted use and redistribution provided that the original author and source are credited.

\section{The Association between Subclinical Hypothyroidism and Components of Metabolic Syndrome}

Khalid S Aljabri ${ }^{1 *}$, Samia A Bokhari ${ }^{1}$, Bandari K Aljabri ${ }^{2}$ and Turki A Alharthi ${ }^{3}$

${ }^{1}$ Department of Endocrinology, Saudi Arabia

${ }^{2}$ Faculty of Medicine, Saudi Arabia

${ }^{3}$ College of Medicine, Saudi Arabia

\begin{abstract}
Background and objective: The burden of thyroid diseases in the general population and patients with Metabolic Syndrome (Mets) is enormous. Therefore, the present study was an effort to investigate the association between Subclinical Hypothyroidism $(\mathrm{SCH})$ and components of Mets in a selected group of patients with Mets in Saudi Arabia.
\end{abstract}

Design: We analyzed retrospectively 798 participants with Mets between the age 20 to 89 years. All patients were from the population of the Primary health center at King Fahad Armed Forces Hospital, Jeddah, Saudi Arabia. Patients with Serum Thyroid Stimulating Hormone (TSH) level $>4.2 \mathrm{MIU} / \mathrm{L}$ and normal free Thyroxine (FT4) level were taken as SCH. Metabolic risk factors were defined using the 2006 IDF criteria.

Result: 798 patients with Mets were included. Patients with SCH were non-significantly older than without $\mathrm{SCH}, 55.0 \pm 12.6$ vs. $53.3 \pm 12.4, \mathrm{p}=0.07$. There were $242(30.3 \%)$ cases with $\mathrm{SCH}$ where female was found in 180 cases $(74.4 \%)$ and male was 62 cases (25.6\%), p=0.009. Patients in the age group of $\geq 60$ years had non-significantly higher prevalence of SCH (36.8\%) compared to $<40$ years (12\%), 40-49 years $(20.2 \%)$ and $50-59$ years $(31 \%), p=0.2$. Cases with $\mathrm{HbA1c}>5.6$ or T2DM, HTN, TG $(\geq 1.7 \mathrm{mmol} / \mathrm{l})$ and low HDL-C were significantly more prevalent in patients with than without SCH $(87.4$ vs. $80.5 \%$, $\mathrm{p}=0.03)$, (56.6 vs. $47.8 \%, \mathrm{p}=0.03)$, ( 52.7 vs. $34.0 \%, \mathrm{p}<0.0001)$ and $(58.7$ vs. $49.7 \%, \mathrm{p}=0.03)$ respectively. SCH with HbA1c $>5.6$ or T2DM, HTN and low HDL-C were increased significantly with advanced ages and non-significantly increased with advanced ages in patients with SCH and TG $(\geq 1.7 \mathrm{mmol} / \mathrm{l})$. Regression analysis of odd ratio of risk factors for patients with $\mathrm{SCH}$ and Mets showed that gender, $\mathrm{BMI} \geq 30 \mathrm{~kg} / \mathrm{m} 2$, HTN, TG ( $\geq 1.7 \mathrm{mmol} / \mathrm{l}$ ) and low HDL-C were associated with higher likely hood of SCH.

Conclusion: Our study suggests that SCH might be a risk factor for Mets and its components. Further investigations are needed to evaluate the mechanism of this correlation.

Keywords: Subclinical hypothyroidism; Components of metabolic syndrome

\section{Introduction}

The Metabolic Syndrome (Mets) includes central obesity, Hyperglycemia Plus Insulin Resistance (IR), Hypertension (HTN), Dyslipidemia [1]. Thyroid Hormones play an important role in regulating Carbohydrate, Lipids and Protein metabolism. There are several studies about the correlation between thyroid function and components of Mets, but the results are disputed. A cross-sectional study of 1581 Euthyroid subjects found that there was positive correlation between Thyroid Stimulating Hormone (TSH) and index of IR as well as Triglyceride (TG) [2]. About one sixth of the Mets patients in Turkey were found to have Subclinical Hypothyroidism (SCH) [3]. Hypothyroidism affects Mets parameters including high density lipoprotein (HDL-C), TG and Fasting Blood Glucose (FBS). Thyroid hormones are major regulatory hormones and may be associated with metabolic syndrome [4,5].

The common pathogenic factor in both the disorders is IR. Many studies have reported a role of IR in causing a significant overlap in diagnosis in Mets population and Hypothyroidism as well [6]. IR subjects are more susceptible to the increased levels of high LDL-C at increasing TSH levels even within the normal range [7]. Among older women, high TSH levels were 
associated with deleterious changes in serum lipids and that women with multiple lipid abnormalities were twice as likely to have increased TSH level [8]. However, studies that evaluate the relation between $\mathrm{SCH}$ and these metabolic disturbances are limited; therefore, the purpose of this study was to analyze the association between SCH and Mets components in a selected group of Mets from Jeddah City, Saudi Arabia.

\section{Method}

We analyzed retrospectively 798 participants with Mets between the age 20 to 89 years. All patients were from the population of the Primary health center at King Fahad Armed Forces Hospital, Jeddah, Saudi Arabia. All data were collected based on a review of electronic medical data. Patient who are pregnant were excluded. The reference range values of TSH $0.22-4.2 \mathrm{mu} / \mathrm{L}$ and Free T4 12.0-22.0pmol/L. Patients with serum TSH level $>4.2 \mathrm{mu} / \mathrm{L}$ and normal FT4 level were taken as SCH. Metabolic risk factors were defined using the 2006 IDF criteria that define elevated TG as $\geq 150 \mathrm{mg} / \mathrm{dL}(\geq 1.7 \mathrm{mmol} / \mathrm{L})$ and reduced HDL-C as $<40 \mathrm{mg} / \mathrm{dL}$ $(<1.03 \mathrm{mmol} / \mathrm{L})$ for male and as $<50 \mathrm{mg} / \mathrm{dL}(<1.29 \mathrm{mmol} / \mathrm{L})$ for female [9]. HTN was defined when the systolic blood pressure was $\geq 130 \mathrm{~mm} \mathrm{Hg}$ and/or diastolic blood pressure was $\geq 85 \mathrm{~mm} \mathrm{Hg}$ in addition to receiving any medication for HTN. Abnormal glucose metabolism was considered when HbA1c $(\geq 5.7)$ or when patients were known to have type 2 diabetes mellitus (T2DM). The total number of cohort were separated on basis of age values into four groups: $<40$ years, $40-49$ years, $50-59$ years and $\geq 60$ years.

\section{Statistical Analysis}

Continuous variables were described using means and Standard Deviations. Univariate analysis of baseline demography both between groups, were accomplished using unpaired t-test and nonparametric and Chi square test were used for categorical data comparison. Regression analysis was performed to assess for Odd Ratio (OR). P value $<0.05$ indicates significance. The statistical analysis was conducted with SPSS version 23.0 for Windows.

\section{Result}

798 patients with Mets were included. There were 158 cases (19.8\%) male and 640 cases $(80.2 \%)$ were female with mean age $53.8 \pm 12.5$ with mean body mass index (BMI) $32.5 \pm 6.3 \mathrm{~kg} / \mathrm{m}^{2}$, (Table 1). HbA1c $>5.6$ or T2DM, HTN, TG $(\geq 1.7 \mathrm{mmol} / \mathrm{l})$ and low HDL-C were present in $82.6 \%, 51.0 \%, 39.7 \%$ and $52.4 \%$ respectively. The mean TSH and FT4 values were $3.6 \pm 2.3 \mathrm{MIU} / \mathrm{l}$ and $15.3 \pm 2.1 \mathrm{pmol} / \mathrm{l}$ respectively. Patients with $\mathrm{SCH}$ were non-significantly older than without $\mathrm{SCH}, 55.0 \pm 12.6$ vs. $53.3 \pm 12.4, \mathrm{p}=0.07$. There were 242 cases $(30.3 \%)$ cases with SCH where female was found in 180 cases (74.4\%) and male was 62 cases $(25.6 \%)$ with male to female ratio of 1 to $2.9, \mathrm{p}=0.009$, (Table 1 ).

Table 1: Base-line characteristics and bivariate analysis for patients with Subclinical hypothyroidism

\begin{tabular}{|c|c|c|c|c|c|}
\hline \multirow{2}{*}{\multicolumn{2}{|c|}{ Parameters }} & \multirow{2}{*}{$\begin{array}{l}\text { Total } \\
\text { Present }\end{array}$} & \multicolumn{2}{|c|}{ Subclinical Hypothyroidism } & \multirow{2}{*}{$P$ Value } \\
\hline & & & Absent & & \\
\hline \multicolumn{2}{|c|}{ Numbers } & 798 & $242(30.3)$ & $556(69.7)$ & \\
\hline \multicolumn{2}{|c|}{ Age (Years) } & $53.8 \pm 12.5$ & $55.0 \pm 12.6$ & $53.3 \pm 12.4$ & 0.07 \\
\hline \multirow{2}{*}{ Gender } & Male & $158(19.8)$ & $62(25.6)$ & $96(17.3)$ & \multirow{2}{*}{0.009} \\
\hline & Female & $640(80.2)$ & $180(74.4)$ & $460(82.7)$ & \\
\hline \multirow{2}{*}{ Body mass index $\left(\mathrm{kg} / \mathrm{m}^{2}\right)$} & Mean \pm SD & $32.5 \pm 6.3$ & $33.3 \pm 6.3$ & $32.1 \pm 6.3$ & 0.02 \\
\hline & $\geq 30$ & $516(65.4)$ & $171(70.7)$ & $345(63.1)$ & 0.04 \\
\hline \multicolumn{2}{|c|}{ HbA1c $>5.6$ or Type 2 diabetes } & $607(82.6)$ & $195(87.4)$ & $412(80.5)$ & 0.03 \\
\hline \multicolumn{2}{|c|}{ Hypertension } & $346(51.0)$ & $137(56.6)$ & $2.9(47.8)$ & 0.03 \\
\hline \multicolumn{2}{|c|}{ Triglyceride $(\geq 1.7 \mathrm{mmol} / \mathrm{l})$} & 315 (39.7) & $127(52.7)$ & $188(34.0)$ & $<0.0001$ \\
\hline \multicolumn{2}{|c|}{ High density lipoprotein $(<1.29 \mathrm{mmol} / \mathrm{l})$} & $398(52.4)$ & $131(58.7)$ & $267(49.7)$ & 0.03 \\
\hline \multicolumn{2}{|c|}{ TSH (MIU/l) } & $3.6 \pm 2.3$ & $6.3 \pm 2.2$ & $2.4 \pm 1.1$ & $<0.0001$ \\
\hline \multicolumn{2}{|c|}{ FT4 (pmol/l) } & $15.3 \pm 2.1$ & $15.0 \pm 2.1$ & $15.4 \pm 2.1$ & 0.02 \\
\hline
\end{tabular}

[mean \pm standard deviation (SD) or number (\%)].

Patients in the age group of $\geq 60$ years had higher prevalence of SCH $(36.8 \%)$ compared to $<40$ years $(12 \%), 40-49$ years $(20.2 \%)$ and 50-59 years (31\%), $\mathrm{p}=0.2$, (Figure 1). Patients with $\mathrm{SCH}$ were significantly have higher BMI than without $\mathrm{SCH}, 33.3 \pm 6.3$ vs. $32.1 \pm 6.3, p=0.02$. Cases with $\mathrm{HbA} 1 \mathrm{c}>5.6$ or T2DM, HTN, TG $(\geq 1.7 \mathrm{mmol} / \mathrm{l}$ ) and low HDL were significantly more prevalent in patients with SCH compared to Euthyroid patients (87.4 vs. $80.5 \%$, $\mathrm{p}=0.03$ ), (56.6vs. $47.8 \%, \mathrm{p}=0.03$ ), (52.7 vs. $34.0 \%, \mathrm{p}<0.0001$ ) and (58.7 vs. $49.7 \%, \mathrm{p}=0.03$ ) respectively. $\mathrm{SCH}$ with $\mathrm{HbA} 1 \mathrm{c}>5.6$ or T2DM, HTN and low HDL were increased significantly with advanced ages ( $p=0.003, p<0.0001$ and $p=0.003$ respectively) and non-significantly increased with advanced ages in patients with SCH and TG ( $\geq 1.7 \mathrm{mmol} / \mathrm{l}$ ) ( $\mathrm{P}=0.6$ ), (Table 2). Regression analysis of odd ratio of risk factors for patients with $\mathrm{SCH}$ and Mets showed that gender, $\mathrm{BMI} \geq 30 \mathrm{~kg} / \mathrm{m}^{2}, \mathrm{HTN}, \mathrm{TG}(\geq 1.7 \mathrm{mmol} / \mathrm{l})$ and low HDL-C were associated with higher likely hood of $\mathrm{SCH},(\mathrm{OR}=1.62 ; 95 \%$ confidence interval $[\mathrm{CI}]=1.01-2.59), \mathrm{p}=0.04),(\mathrm{OR}=2.26 ; 95 \% \mathrm{CI}=1.48-3.45)$, $\mathrm{p}<0.0001),(\mathrm{OR}=2.27 ; 95 \% \mathrm{CI}=1.46-3.52), \mathrm{p}<0.0001),(\mathrm{OR}=2.67$; $95 \% \mathrm{CI}=1.81-3.94), \mathrm{p}<0.0001)$ and $(\mathrm{OR}=3.49 ; 95 \% \mathrm{CI}=2.30-5.31)$, $\mathrm{p}<0.0001$ ) respectively, (Table 3 ). 
Table 2: Comparison between metabolic syndrome components and age groups for patients with subclinical hypothyroidism [Number (\%)].

\begin{tabular}{|c|c|c|c|c|c|}
\hline \multirow{2}{*}{ Parameters } & \multicolumn{4}{|c|}{ Age (Years) } & \multirow{2}{*}{ P value } \\
\cline { 2 - 5 } & $<\mathbf{4 0}$ & $\mathbf{4 0 - 4 9}$ & $\mathbf{5 0 - 5 9}$ & $\mathbf{2 6 0}$ \\
\hline Numbers & $99(12.4)$ & $189(23.7)$ & $255(32.0)$ & $255(32.0)$ & \\
\hline HbA1c $>5.6$ or Type 2 diabetes & $16(8.2)$ & $40(20.5)$ & $59(30.3)$ & $80(41.0)$ & 0.003 \\
\hline Hypertension & $6(4.4)$ & $20(14.6)$ & $45(32.8)$ & $66(48.2)$ & $<0.0001$ \\
\hline Triglyceride $(\geq 1.7 \mathrm{mmol} / \mathrm{l})$ & $12(9.4)$ & $26(20.5)$ & $42(33.1)$ & $47(37.0)$ & 0.6 \\
\hline High density lipoprotein $(<1.29 \mathrm{mmol} / \mathrm{l})$ & $18(13.7)$ & $29(22.1)$ & $40(30.5)$ & $44(33.6)$ & 0.003 \\
\hline
\end{tabular}

Table 3: Regression analysis for odd ratio of risk factors for patients with subclinical hypothyroidism in patients with metabolic syndrome

\begin{tabular}{|c|c|c|}
\hline Parameters & Odd Ratio & P value \\
\hline Age (years) & $\mathbf{1 . 0 0}(\mathbf{0 . 9 9 - 1 . 0 2 )}$ & $\mathbf{0 . 4}$ \\
\hline Gender & $1.62(1.01-2.59)$ & 0.04 \\
\hline Body mass index $\left(\mathrm{kg} / \mathrm{m}^{2}\right) \geq 30$ & $2.26(1.48-3.45)$ & $<0.0001$ \\
\hline HbA1c $>5.6$ or Type 2 diabetes & $1.37(0.82-2.30)$ & 0.2 \\
\hline Hypertension & $2.27(1.46-3.52)$ & $<0.0001$ \\
\hline Triglyceride $(\geq 1.7 \mathrm{mmol} / \mathrm{l})$ & $2.67(1.81-3.94)$ & $<0.0001$ \\
\hline High density lipoprotein $(<1.29 \mathrm{mmol} / \mathrm{l})$ & $3.49(2.30-5.31)$ & $<0.0001$ \\
\hline
\end{tabular}

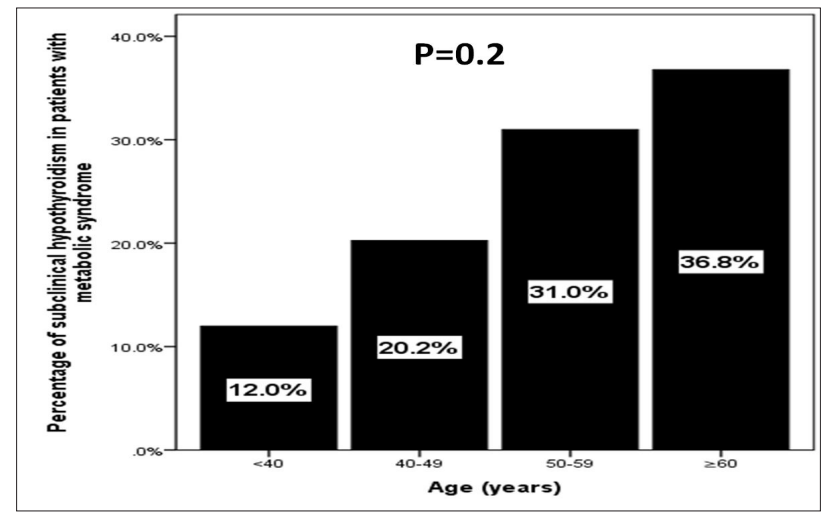

Figure 1: The prevalence of hypothyroidism in patients with metabolic syndrome in correlation to age groups..

\section{Discussion}

High prevalence of Mets is a global phenomenon. Hypothyroidism and Mets are recognized risk factors for atherosclerotic cardiovascular disease. The aim of the present study was to analyze the association between SCH and Mets components in adult population from Jeddah City, Saudi Arabia. In the present population-based study of 798 patients with Mets, we found a significant association between SCH and components of Mets. The above results agree with previous studies showing an association between Mets and SCH [2,3,10-16]. Garcia et al. [11] reported that there was no association between Mets or its components and subclinical Thyroid Dysfunction. A study in Taiwan explored the serum TSH levels and Mets components and concluded that even slight increases in TSH, as in SCH, may be a Mets risk factor.

Lai [14] Another study concluded that Higher TSH levels in SCH with a TSH $>10 \mathrm{MIU} / \mathrm{l}$ are associated with increased odds of prevalent Mets [15]. Moreover, even high normal TSH levels and low normal free T4 levels were significantly associated with increased prevalence of Mets, which may be of importance when evaluating such subjectsx $[2,16]$. Mets is increased in patients with hypothyroidism and suggested that hypothyroidism be considered in newly diagnosed Mets patients [12]. In accordance with the above-mentioned studies, we have found increased risk of Mets in $\mathrm{SCH}$.

We found that patients with $\mathrm{SCH}$ were non-significantly older than without $\mathrm{SCH}, 55.0 \pm 12.6$ vs. $53.3 \pm 12.4, \mathrm{p}=0.07$. $\mathrm{SCH}$ with $\mathrm{HbA} 1 \mathrm{c}>5.6$ or T2DM, HTN and low HDL were increased significantly with advanced ages $(\mathrm{p}=0.0 .003, \mathrm{p}<0.0001$ and $\mathrm{p}=0.0 .003$ respectively) and non-significantly increased with advanced ages in patients with SCH and TG ( $\geq 1.7 \mathrm{mmol} / \mathrm{l})(\mathrm{P}=0.6)$, (Table 2). Among the study population, the prevalence of $\mathrm{SCH}$ is significantly more in female (74.4\% vs. $25.6 \%, \mathrm{p}=0.009)$ and earlier 
studies shows that the thyroid dysfunction was common in females with mets $[17,18]$. Previous studies reported a high prevalence of subclinical hypothyroidism among female with Metabolic Syndrome [17].

In our study, like the Virta study the prevalence of obesity with subclinical hypothyroid was higher than in euthyroid cases [19]. It has been shown that in adipocytes and pre adipocytes expressed TSH receptors, TSH binds with its receptors and induces pre adipocytes to produce and release adipokines, a mechanism which may explain the correlation between TSH levels and obesity [20]. The current analyses suggest that HTN was the metabolic factor that significantly associated with the occurrence of SCH. This relationship may reflect the observation that HTN is the most common manifestation within the myriad of at-risk phenotypes associated with atherosclerotic cardiovascular disease. Furthermore, among all the possible pathological pathways leading to HTN, several share a link with hypothyroidism including changes in circulating catecholamines, disturbances in the Renin-Angiotensin-Aldosterone system, and increased peripheral vascular resistance [21-23].

In this study, the HbA1c $>5.6$ or T2DM, TG ( $\geq 1.7 \mathrm{mmol} / \mathrm{l})$ were significantly higher and low HDL-C levels were significantly lower in the SCH patients with Mets than in the patients without SCH. These findings were similar to those obtained in the studies on Hispanic population by Garcia et al. [11 ] and on Chennai urban population by Shantha et al. [11,24] It has been shown that as a result of decline in the number hepatocytes cell-surface receptors for LDL, resulting in reduced LDL catabolism in women with overt hypothyroidism leads to reductions in HDL-C [25-27]. However, the results of population studies about the correlation between Thyroid function and Lipid profiles are controversial. Association of SCH with components of Mets was assessed by multiple logistic regression analysis in the present study. Gender, BMI $\geq 30 \mathrm{~kg} / \mathrm{m}^{2}$, HTN, TG and HDL-C showed significant association with $\mathrm{SCH}$ in persons with Mets whereas there was no statistically significant association with age and $\mathrm{HbA} 1 \mathrm{c}>5.6$ or T2DM, (Table 3 ).

In a retrospective study, Razvi et al. [28] found treatment of SCH with levothyroxine was associated with fewer ischemic heart disease events in the younger individuals, supporting a beneficial effect of thyroid hormone on cardiovascular risk factors in hypothyroid patients [28]. Whether Thyroid Dysfunction has a major direct effect, or is just an intermediate mediator, or simply a "Bystander" in these many pathways leading to coronary atherosclerosis needs to be continuously monitored. Thus, exploring the reverse relationship between Mets and thyroid dysfunction as well as the temporal sequence of association of Mets, thyroid dysfunction, and cardiovascular diseases may be a worthwhile topic for future research. Furthermore, the efficacy of hypothyroidism medicine to prevent the development of Mets should also be investigated in future studies we aimed to identify the prevalence of SCH in patients with Mets in primary health care setting.

Furthermore, due to the retrospective nature of this study, the observed population reflects a selected yet comprehensive group of patients rather than the general population. Our study could be limited by the question of clustering of cases within the study region and the effect that might have on our estimates, in addition, the current study population may appear limited in size and therefore may underestimate the true frequency of SCH in the general population. In addition, the study shares the limitations of all retrospective studies. In conclusion, our study suggests that SCH might be a risk factor for Mets and its components. Further investigations are needed to evaluate the mechanism of this correlation.

\section{Acknowledgement}

The author would like to thank all colleagues from the Department of primary care for helping in data collection.

\section{References}

1. Pandey S, Baral N, Majhi S, Acharya P, Karki P, et al. (2009) Prevalence of the metabolic syndrome in acute myocardial infarction and its impact on hospital outcomes. Int J Diab Dev Ctries 29(2): 52-55.

2. Roos A, Bakker SJ, Links TP, Gans RO, Wolffenbuttel BH, et al. (2007) Thyroid function is associated with components of the metabolic syndrome in euthyroid subjects. J Clin Endocrinol Metab 92(2): 491-496.

3. Uzunlulu M, Yorulmaz E, Oguz A (2007) Prevalence of subclinical hypothyroidism in patients with metabolic syndrome. Endocr J 54(1): 71-76.

4. Shrestha S, Das BKL, Baral N, Chandra L (2007) Association of metabolic syndrome and its components with thyroid dysfunction in females. Int J Diab DeV Ctries (27):24-26.

5. Dillmann WH (1985) Mechanism of action of thyroid hormones. Med Clin North America 69(5): 49-61.

6. Meher LK, Raveendranathan SK, Kota SK, Sarangi J, Jali SN, et al. (2013) Prevalence of hypothyroidism in patients with metabolic syndrome. Thyroid Res Pract 10(2): 60-64.

7. Bakker SJ, Maaten JC, Popp Snijders C, Slaets JP, et al. (2001) The relationship between thyrotropin and low-density lipoprotein cholesterol is modified by insulin sensitivity in healthy euthyroid subjects. J Clin Endocriol Metab 86(3): 1206-1211.

8. Bauer DC, Ettinger B, Browner WS (1998) Thyroid functions and serum lipids in older women: a population-based study. Am J Med 104(6): 546551.

9. KGMM Alberti, Zimmet P (2006) Metabolic syndrome a new worldwide definition. A consensus statement from the International Diabetes Federation. Diabetic Medicine 23(5): 469-480.

10. Canaris GJ, Manowitz NR, Mayor G, Ridgway EC (2000) The Colorado thyroid disease prevalence study. Arch Intern Med 160(4): 526-534.

11. Garduño Garcia J de J, Alvirde Garcia U, López Carrasco G, Padilla Mendoza ME, Mehta R, et al. (2010) TSH and free thyroxine concentrations are associated with differing metabolic markers in euthyroid subjects. Eur J Endocrinol 163(2): 273-278.

12. Erdogan M, Canataroglu A, Ganidagli S, Kulaksızoglu M (2011) Metabolic syndrome prevalence in subclinic and overt hypothyroid patients and the relation among metabolic syndrome parameters. J Endocrinol Invest 34(7): 488-492.

13. Ogbera AO, Kuku S, Dada O (2012) The metabolic syndrome in thyroid disease A report from Nigeria. Indian J Endocrinol Metab 16(3): 417422.

14. Lai Y, Wang J, Jiang F, Wang B, Chen Y, et al. (2011) The relationship between serum thyrotropin and components of the metabolic syndrome Endocrine J 58(1): 23-30. 
15. Waring AC, Rodondi N, Harrison S, Kanaya AM, Simonsick EM, et al. (2012) Thyroid function and prevalent and incident metabolic syndrome in older adults: The Health Ageing and Body Composition Study. Clin Endocrinol 76(6): 911-918.

16. Lee YK, Kim JE, Oh HJ, Park KS, Kim SK, et al. (2011) Serum TSH level in healthy Koreans and the association of TSH with serum lipid concentration and metabolic syndrome. Korean J Intern Med 26(4): 432-439.

17. Gaurav A, Sudhakar MK, Mohini S, Senthil N, Amarbalan R, et al. (2011) The prevalence of thyroid dysfunction among South Indian women with Metabolic Syndrome. Journal of Clinical and Diagnostic Research 5(2) 213-216.

18. Reaven GM (1988) Role of insulin resistence in human disease. Diabetes 37(12): 1595-607.

19. Virta LJ, Eskelinen SI (2011) Prevalence of hypothyroidism in Finland a nationwide prescription study. Eur J Clin Pharmacol 67(1): 73-77.

20. Bastemir M, Akin F, Alkis E, Kaptanoglu B (2007) Obesity is associated with increased serum TSH level, independent of thyroid function. Swiss Med Wkly 137(29-30): 431-434.

21. Oparil S, Zaman MA, Calhoun DA (2013) Pathogenesis of hypertension Annals of internal medicine 139(9): 761-776.
22. Fletcher AK, Weetman AP (1998) Hypertension and hypothyroidism. Journal of Human Hypertension 12: 79-82.

23. Stabouli S, Papakatsika S, Kotsis V (2010) Hypothyroidism and hypertension. Expert review of cardiovascular therapy 8: 1559-1565.

24. Shantha GP, Kumar AA, Jeyachandran V, Rajamanickam D, Rajkumar K, et al. (2009) Association between primary hypothyroidism and metabolic syndrome and the role of $\mathrm{C}$ reactive protein: A cross sectional study from South India. Thyroid Res 2(1): 2.

25. Jung CH, Sung KC, Shin HS, Rhee EJ, Lee WY, et al. (2003) Thyroid dysfunction and their relation to cardiovascular risk factors such as lipid profile, hsCRP, and waist hip ratio in Korea. Korean J Intern Med 18(3): $146-1453$

26. Engler H, Riesen WF (1993) Effect of thyroid function on concentrations of lipoprotein(a). Clin Chem 39: 2466-2469.

27. Takashima N, Niwa Y, Mannami T, Tomoike H, Iwai N (2007) Characterization of subclinical thyroid dysfunction from cardiovascular and metabolic viewpoints: the Suita study. Circ J 71(2): 191-195.

28. Razvi S, Weaver JU, Butler TJ, Pearce, SH (2012) Levothyroxine treatment of subclinical hypothyroidism, fatal and nonfatal cardiovascular events, and mortality. Arch Intern med 172(10): 811-817. 